\title{
Grit protects medical students from burnout: a longitudinal study
}

\author{
Muhammad Raihan Jumat ${ }^{1}$, Pierce Kah-Hoe Chow ${ }^{1,2}$, John Carson Allen $\mathrm{Jr}^{1}$, Siang Hui Lai ${ }^{1,2}$, Nian-Chih Hwang ${ }^{1,2}$, \\ Jabed lqbal ${ }^{1,2}$, May Un Sam Mok², Attilio Rapisarda', John Matthew Velkey ${ }^{3}$, Deborah Lynn Engle ${ }^{3}$ and \\ Scott Compton ${ }^{1 *}$ (D)
}

\begin{abstract}
Background: Burnout is a serious issue plaguing the medical profession with potential negative consequences on patient care. Burnout symptoms are observed as early as medical school. Based on a Job Demands-Resources model, this study aims to assess associations between specific job resources measured at the beginning of the first year of medical school with burnout symptoms occurring later in the first year.

Methods: The specific job resources of grit, tolerance for ambiguity, social support and gender were measured in Duke-NUS Medical School students at the start of Year 1. Students were then surveyed for burnout symptoms at approximately quarterly intervals throughout the year. Using high ratings of cynicism and exhaustion as the definition of burnout, we investigated the associations of the occurrence of burnout with student job resources using multivariable logistic regression analysis.

Results: Out of 59 students, 19 (32.2\%) indicated evidence of burnout at some point across the first year of medical school. Stepwise multivariable logistic regression analysis identified grit as having a significant protective effect against experiencing burnout (Odds Ratio, $0.84 ; 95 \% \mathrm{Cl} 0.74$ to 0.96). Using grit as a single predictor of burnout, area under the ROC curve was 0.76 ( $95 \% \mathrm{Cl}: 0.62$ to 0.89 ).

Conclusions: Grit was identified as a protective factor against later burnout, suggesting that less gritty students are more susceptible to burnout. The results indicate that grit is a robust character trait which can prognosticate burnout in medical students. These students would potentially benefit from enhanced efforts to develop grit as a personal job resource.
\end{abstract}

Keywords: Grit, Burnout, Medical education, Tolerance for ambiguity, Engagement, Medical school

\section{Background}

Since May 2019, the World Health Organization (WHO) has included burnout in the 11th Revision of the International Classification of Diseases (ICD-11) as an occupational phenomenon. Burnout is conceptualized and defined as an unsuccessfully managed syndrome resulting from chronic workplace stress [1]. Burnout is

\footnotetext{
* Correspondence: scott.compton@duke-nus.edu.sg

'Office of Education, Duke-NUS Medical School, 8 College Rd., Level 3, Singapore 169857, Singapore

Full list of author information is available at the end of the article
}

typically characterized by emotional exhaustion, cynicism and/or a perception of reduced professional accomplishment $[1,2]$. Individuals in careers requiring close interactions with other people are most susceptible to burnout [3], this makes healthcare workers particularly prime for developing burnout [4].

Numerous reports have shown that medical professionals all over the world at all career stages are succumbing to the scourge of burnout [4-10]. Doctors experiencing burnout fall ill more frequently, are more prone to making medical errors, and have a higher

(c) The Author(s). 2020 Open Access This article is licensed under a Creative Commons Attribution 4.0 International License, which permits use, sharing, adaptation, distribution and reproduction in any medium or format, as long as you give appropriate credit to the original author(s) and the source, provide a link to the Creative Commons licence, and indicate if changes were made. The images or other third party material in this article are included in the article's Creative Commons licence, unless indicated otherwise in a credit line to the material. If material is not included in the article's Creative Commons licence and your intended use is not permitted by statutory regulation or exceeds the permitted use, you will need to obtain permission directly from the copyright holder. To view a copy of this licence, visit http://creativecommons.org/licenses/by/4.0/ The Creative Commons Public Domain Dedication waiver (http://creativecommons.org/publicdomain/zero/1.0/) applies to the data made available in this article, unless otherwise stated in a credit line to the data. 
tendency to leave the profession [11]. In extreme conditions, burnout can result in depression which adversely affects physician health and performance [12]. When physician health deteriorates, patient care suffers [13].

Burnout can be observed as early as medical school, where medical students from various countries are reporting higher incidences of burnout when compared to their non-medical student counterparts [6]. Students experiencing burnout have shown inability to connect with others [14], a strong desire to leave the institution and the profession [15, 16], and higher likelihood of suicidal ideation [17]. This observation is particularly distressing considering that matriculating medical students are generally optimistic and engaged [18]. Following matriculation, medical students report increasing incidence of burnout throughout the course of medical school $[19,20]$. Reasons for the high burnout rate amongst medical students include the heavy cognitive load, intense competition among classmates, and constant exposure to death and suffering [21,22].

While the symptoms and effects of burnout have been previously established, factors which may help mitigate or predict burnout are less obvious. One recently suggested potential mitigating factor for burnout is grit, defined as passion and sustained persistence applied toward longterm achievement [23]. However, the evidence suggesting this association was from a cross-sectional study of doctors in the United Kingdom [24]. Nonetheless, the potential for grit-a modifiable factor [25], represents an enticing target to mitigate burnout. Other factors which have been shown to affect psychological well-being and improved life satisfaction include tolerance for ambiguity (TFA) [26], religiosity [27, 28], and social support [29].

The primary aim of this study is to determine if grit, tolerance for ambiguity (TFA), religiosity and/or social support are predictive of burnout in year one medical students. The secondary aim is to determine the prognostic utility of these factors in predicting burnout in the first year of medical school. We hypothesize that a student possessing protective resources will be at lower risk of reporting incidences of burnout over the course of an academic year. Students lacking protective job resources would be at a higher risk of burnout and thus should be monitored regularly. In assessing risk of burnout, we carried out a panel survey of Year 1 students entering Duke-NUS Medical School and typed them for the character traits listed previously at the start of the academic year. These students were subsequently followed up for incidences of burnout at three time points during the academic year.

\section{Methods}

\section{Conceptual framework}

The conceptual framework of the study is based on the Job Demands-Resources model [30]. In this model every job has its own specific risk factors which are classified as job demands and job resources.

Job demands are psychological, physical, social or organizational aspects of the job which require sustained physical and/or psychological effort or skills and are therefore associated with certain physiological and/or psychological costs.

Job resources refer to physical, psychological, social or organizational aspects of the job that function in achieving work goals, reduce job demands and the associated psychological and physical costs and/or stimulate personal growth and development. These resources may be located at the level of the organization (e.g., salary, career opportunities, job security), interpersonal and social relations (work support groups, work team dynamics), work organization (role clarity), or the level of the task (autonomy, performance feedback).

In general, job resources and job demands are antagonistic. Job demands, such as high work pressure and emotionally demanding interactions, would necessitate mobilisation of job resources. Recent publications have shown that personal resources as well have an antagonistic role to job demands and hence should be categorized as job resources [31-33]. An individual possessing sufficient resources to support the demands of a job is engaged and not emotionally strained. But when resources are lacking, the individual is at risk of developing emotional exhaustion, cynicism, and reduced work efficacy which are a prelude to burnout [30, 34]. This is further exacerbated by poor working conditions, a high work load combined by understaffing and a perceived lack of control as often experienced by healthcare workers and medical students.

Resources measured in this study, which can be invoked by medical students to parry the intense demands of medical school, are grit, religiosity, social support and comfort with uncertainty. While we recognise that the choice of resources is not exhaustive, these factors have been shown to be protective against burnout in the literature. Grit is defined as passion and sustained persistence applied toward long-term achievement [23, 35]. The relationship between grit and burnout has been expounded in the background section. Religiosity is defined as the adherence to beliefs, doctrines, ethics, rituals, texts, traditions, and practices related to a higher power and associated with an organized group [36]. Studies on religiosity and burnout amongst medical students have shown conflicting results with some indicating lack of a relationship [37] and others showing an inverse relationship [38, 39]. Social support is the perception of the quality of emotional support provided by others [40]. Studies have also indicated that medical students who perceive a lack of social support have a higher tendency to undergo depression and burnout [41]. TFA 
is defined as the degree to which an individual is comfortable operating under conditions of uncertainty, unpredictability, conflicting directions and multiple demands [42]. Physicians with low TFA scores are more prone to develop burnout [43], but this correlation has not been reported in medical students. Lastly, burnout rates were compared to the gender make-up of the class. Studies on gender differences and mental health in medical students have shown varying results. Some studies have shown that no difference exists between the sexes in predicting burnout $[44,45]$. Some report that males are at a higher risk $[20,46]$, while some indicate that female medical students are more vulnerable $[47,48]$.

\section{Methodology /student survey}

A study of the class of 2021 students at Duke-NUS Medical School during year 1 was conducted using survey methodology. Duke-NUS Medical School is an American style, graduate-entry, allopathic medical school in Singapore. The panel survey consisted of demographic questions with questionnaires measuring the four job resources of grit, religiosity, social support and TFA, as well as symptoms of burnout.

Burnout was measured using the validated Maslach Burnout Inventory-Student Survey (MBI-SS), which has become the gold-standard for defining burnout, especially amongst medical students [17, 49-51]. The MBI-SS uses three different subscales: Emotional Exhaustion, Cynicism and Personal Inefficacy with a high score on any of these sub-scales indicating burnout [2]. Grit was measured by a 12-item Grit scale [35]. An uncorrected score of 60 indicates that an individual is extremely gritty while the lowest score on the scale indicates that the individual is not gritty at all [23]. Similar to other studies [52, 53], grit is expressed as a single factor. Religiosity was measured using the Duke University Religion Index (DUREL), which is a five-item scale made up of three dimensions: intrinsic religiosity (3 items), organizational religiosity ( 1 item), and non-organizational religiosity (1 item), measured on a 5point Likert scale [54]. The Multidimensional Scale of Perceived Social Support (MPSS) was used to measure the availability of social support an individual perceives they are receiving from the family, friends and a significant other [55]. TFA was measured by a seven-item TFA scale (TAS). The TAS measures the student's ability to cope with situations of uncertainty. Students ranked their responses to the 7 items on the TAS on a 6 response Likert scale. Scores ranged from 7 (lowest tolerance for ambiguity) to 42 (highest tolerance for ambiguity) [56].

The survey was created on an online platform, and a link to the survey was sent out to the Duke-NUS medical school mailing list. The first sampling point $\left(T_{1}\right)$ was from 22nd August - 5th September 2017, at which time all 4 job resources and burnout were surveyed. For the next three sampling points, 1st November - 10th November $2017\left(\mathrm{~T}_{2}\right)$, 1st February - 10th February 2018 $\left(\mathrm{T}_{3}\right)$, and 1st May - 10th May $2018\left(\mathrm{~T}_{4}\right)$, only burnout was surveyed. Students indicated their consent electronically before attempting the survey. The study was approved by the National University of Singapore Institutional Review Board.

\section{Statistical analysis}

Baseline characteristics were summarized using the mean and standard deviation (SD) for burnout and the job resources (grit, religiosity, social support and TFA). To assess the internal consistency of responses, Cronbach's alpha was calculated for each scale (or subscale in the case of burnout). Summary statistics of survey instruments are reported for all responders in terms of numbers and percentages or mean scores and standard deviations, as appropriate.

Univariate logistic regression analysis was conducted on grit, religiosity, social support, and TFA to assess protective associations against burnout. For the purpose of this study, a student was considered as experiencing burnout if they scored high on both the emotional exhaustion and cynicism sub-scales of the MBI-SS, as used by several recent studies $[24,57,58]$. A student that did not register high on both of these sub-scales was scored as 'NO BURNOUT'. Conversely, students scoring high on any of these sub-scales at least once in the study period are labelled as 'BURNOUT'. While burnout is not recognised as a distinct disorder in the Diagnostic and Statistical Manual of Mental Disorders (DSM) [59], it is recognised in the 11th revision of the International Classification of Diseases (ICD-11) [1]. This allowed for the tentative classification of BURNOUT or NO BURNOUT according to the responses to the MBI-SS. To address the first research objective, the resources of grit, religiosity, social support and TFA were compared between students who did not experience burnout to those who reported burnout at least once during the year. Results were summarized as odds ratios (ORs) and 95\% confidence intervals (CIs) reflecting the protective effect for NO BURNOUT. Predictive capabilities of resources demonstrating statistically significant protective effects against burnout (NO BURNOUT) were summarized using a Receiving Operating Characteristic (ROC) curve and negative (NPV) and positive predictive value (PPV) with a statistically optimal cut-point indicated by the Youden J-statistic. All statistical analyses were performed with SAS version 9.4. Statistical significance was set at $P<0.05$.

\section{Results}

\section{Reliability statistics}

Internal reliability of survey instruments used in this study was compared to previous values found in the 
literature. The obtained reliability statistics (Cronbach's alpha) for the MBI-SS scale were $0.76,0.85$, and 0.76 for emotional exhaustion, professional efficacy and cynicism, respectively. This is similar to previously reported Cronbach's alpha: 0.76, 0.90, and 0.76 [60]. The Cronbach's alpha received from the TFA scale was 0.81 , while other studies have previously reported 0.75 [42]. The responses from the DUREL scale in this study had a Cronbach's alpha of 0.90 , previous studies have a range of 0.78 to 0.91 [61]. The Cronbach's alpha from the Grit scale used in this study was 0.81 , while other studies have showed a range of 0.77 to 0.85 [23]. The four different sub-scales of the MPSS generated Cronbach alpha values of $0.95,0.84,0.91$, and 0.87 for significant other, family friends, and overall, respectively. Previous studies have shown a value range of 0.88 to 0.92 [62]. Overall, the obtained reliability statistics (Cronbach's alpha) closely matched previously reported values.

\section{Descriptive statistics}

The panel survey attained a response rate of 93.7\% (59/ 63 students) for all timepoints. Fifty-nine out of $63 \mathrm{stu}-$ dents (response rate 93.7\%) responded to the surveys at all timepoints. None of the respondents dropped out of the study. The responses of these 59 students were analysed in this study. Descriptive statistics for survey instruments are shown in (Table 1). Burnout, religiosity, and social support are listed by their respective subscales. When only considering students who reported high scores on the emotional exhaustion and cynicism subscales, 19 students reported high MBI-SS scores at least once over the course of the academic year. This constitutes $32.2 \%$ out of the 59 responders.

\section{Multivariable statistical analysis}

Subsequent analysis compared demographics between the different job resources, as well as gender, for the predicted outcome of 'NO BURNOUT'. The statistical analyses focused on the 40 students who had low MBI-SS scores throughout the study period versus the 19 students who reported at least 1 incidence of burnout over the academic year. Stepwise multivariable logistic regression analysis identified grit as the single job resource significantly predictive of the NO BURNOUT outcome $(p<0.01)$. A one-unit increase in grit was reflected in a $19 \%$ average increase in the odds of NO BURNOUT $(\mathrm{OR}=1.19 ; 95 \%$ CI: 1.04, 1.36) (Table 2).

Area under the grit ROC curve as a predictor for NO BURNOUT was 0.76, (95\% CI: 0.63, 0.89) (Fig. 1). An uncorrected grit cut-off score of 44 was indicted as the statistically optimal threshold for discrimination of $\mathrm{NO}$ BURNOUT (Youden J-statistic $=0.49$ ), with associated positive and negative predictive values for NO BURNOUT outcome of PPV $=0.92$ and NPV $=0.52$, respectively (Table 3). Only 2 of 26 students (7.7\%) with grit score $\geq 44$ reported high MBI-SS scores. Conversely, 33 students had grit score $<44$, with $17(51.5 \%)$ reporting high MBI-SS scores and 16 (48.5) had low MBI-SS scores (Fig. 2).

\section{Discussion}

Grit was the only job resource studied that exhibited a correlation with a reduced risk of burnout. That is, a

Table 1 Summary of survey instrument results (mean \pm standard deviation) at the 4 study sampling times $(N=59)$

\begin{tabular}{|c|c|c|c|c|}
\hline Survey Instrument & $\mathrm{T}_{1}$ & $\mathrm{~T}_{2}$ & $T_{3}$ & $\mathrm{~T}_{4}$ \\
\hline \multicolumn{5}{|l|}{ BURNOUT } \\
\hline Emotional Exhaustion & $13.2 \pm 5.2$ & $13.2 \pm 4.9$ & $11.6 \pm 5.4$ & $11.8 \pm 4.6$ \\
\hline Professional Efficacy & $25.6 \pm 5.9$ & $23.8 \pm 6.0$ & $24.8 \pm 4.9$ & $24.8 \pm 5.5$ \\
\hline Cynicism & $6.4 \pm 4.7$ & $7.7 \pm 5.7$ & $8.1 \pm 6.1$ & $7.6 \pm 5.6$ \\
\hline TOLERANCE FOR AMBIGUITY & $20.6 \pm 5.5$ & - & - & - \\
\hline \multicolumn{5}{|l|}{ RELIGIOSITY } \\
\hline Organizational Religious Activity (ORA) & $2.8 \pm 1.8$ & - & - & - \\
\hline Non-Organizational Religious Activity (NORA) & $2.5 \pm 1.8$ & - & - & - \\
\hline Intrinsic Activity (IR) & $8.6 \pm 4.0$ & - & - & - \\
\hline GRIT & $3.6 \pm 0.5$ & - & - & - \\
\hline \multicolumn{5}{|l|}{ SOCIAL SUPPORT } \\
\hline Significant Other & $5.6 \pm 1.3$ & - & - & - \\
\hline Family & $5.7 \pm 1.0$ & - & - & - \\
\hline Friends & $5.7 \pm 0.8$ & - & - & - \\
\hline Overall & $5.7 \pm 0.8$ & - & - & - \\
\hline
\end{tabular}

$\mathrm{T}_{1}:$ 22nd August - 5th September 2017, $\mathrm{T}_{2}: 1$ st November - 10th November 2017, $\mathrm{T}_{3}:$ 1st February 2018- 10th February 2018, $\mathrm{T}_{4}: 1$ st May - 10 th May 2018 
Table 2 Analysis of study variables as predictors of NO BURNOUT

\begin{tabular}{|c|c|c|c|c|c|c|}
\hline \multirow{3}{*}{$\begin{array}{l}\text { Parameter } \\
\text { Female Gender }\end{array}$} & \multicolumn{2}{|l|}{ CHI SQUARE } & \multicolumn{4}{|c|}{ ODDS RATIO ESTIMATES } \\
\hline & \multirow{2}{*}{$\begin{array}{l}\text { Wald Chi-Square } \\
0.48\end{array}$} & \multirow{2}{*}{$\begin{array}{l}\boldsymbol{p} \text {-value } \\
0.49\end{array}$} & \multirow{2}{*}{$\frac{\text { B-Value }}{0.45}$} & \multirow{2}{*}{$\begin{array}{l}\text { Point Estimate } \\
1.56\end{array}$} & \multicolumn{2}{|c|}{ 95\% Wald Confidence Limits } \\
\hline & & & & & 0.44 & 0.45 \\
\hline Tolerance for Ambiguity & 0.06 & 0.81 & 0.02 & 1.02 & 0.90 & 0.02 \\
\hline Religiosity & 0.31 & 0.58 & -0.05 & 0.95 & 0.81 & -0.05 \\
\hline Grit & 6.77 & $<0.01$ & 0.17 & 1.19 & 1.04 & 0.17 \\
\hline Social Support & 0.77 & 0.38 & 0.03 & 1.03 & 0.96 & 0.03 \\
\hline
\end{tabular}

grittier student is less likely to score high on the MBI-SS over the course of the first academic year of medical school. The AUC of 0.76 under the ROC curve indicates that grit would be considered a moderately accurate predictor of burnout among medical students. Interestingly, grit was only measured at the start of the school year, and yet it allowed for the accurate prediction of the scores on the MBI-SS, across four different timepoints across the year. School administrators might use the grit scale to predict and anticipate for burnout amongst medical students.

Regarding the second research question, based on study results, a student having a grit score of $\geq 44$ would have an estimated $92 \%$ chance of not experiencing burnout. Students having a grit score of $<44$ are indicated to have almost equal probability of experiencing burnout or not. Hence high grit, as a predictor, has high specificity and low sensitivity in predicting NO BURNOUT. The data from this study points to high grit as an effective job resource in preventing the onset of burnout in medical students.

We have chosen to identify students with high scores of emotional exhaustion and cynicism as having burnout. Personal inefficiency, the third component of burnout, was not considered as emotional exhaustion and cynicism have been shown to be more strongly linked to burnout [63-67]. Several other studies have also chosen to only use emotional exhaustion and cynicism as indicators of burnout $[24,57,58]$. The conclusion that grit and burnout are correlated is also reached when

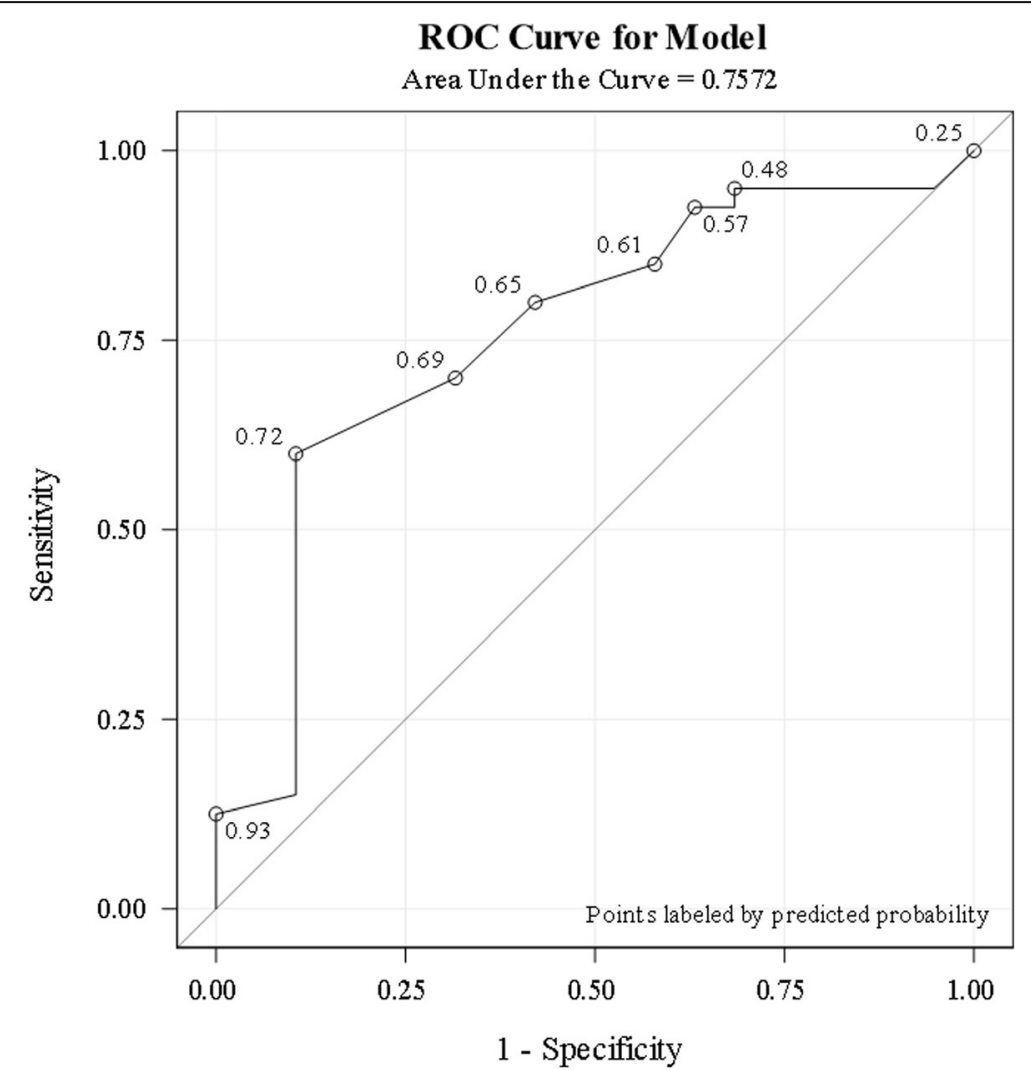

Fig. 1 Receiver Operating Characteristic (ROC) Curve for grit score as a predictor of NO BURNOUT'. Area under curve (AUC; (95\% Confidence Interval): $0.76(0.63,0.89))$ 
Table 3 ROC Curve cut-points with positive and negative predictive values (NPV and PPV) for predicted outcome of NO BURNOUT

\begin{tabular}{llll}
\hline GRIT Score & PPV & NPV & Youden J \\
\hline 32 & 0.68 &. & 0.00 \\
34 & 0.68 & 0.33 & 0.00 \\
35 & 0.70 & 0.60 & 0.11 \\
36 & 0.72 & 0.67 & 0.16 \\
37 & 0.73 & 0.71 & 0.21 \\
38 & 0.75 & 0.75 & 0.27 \\
39 & 0.74 & 0.67 & 0.24 \\
40 & 0.76 & 0.70 & 0.29 \\
41 & 0.76 & 0.57 & 0.27 \\
42 & 0.80 & 0.58 & 0.38 \\
43 & 0.82 & 0.52 & 0.38 \\
44 & 0.92 & 0.52 & 0.49 \\
45 & 0.91 & 0.46 & 0.39 \\
47 & 0.88 & 0.40 & 0.24 \\
48 & 0.86 & 0.38 & 0.19 \\
50 & 0.83 & 0.36 & 0.14 \\
51 & 0.75 & 0.33 & 0.04 \\
55 & 1.00 & 0.35 & 0.10 \\
56 & 1.00 & 0.34 & 0.08 \\
57 & 1.00 & 0.33 & 0.05 \\
59 & 1.00 & 0.33 & 0.03 \\
\hline
\end{tabular}

*Uncorrected grit score values (Grit Score $\times 12$ )

An uncorrected grit cut-off score of 44 was indicated as the statistically optimal threshold for discrimination of NO BURNOUT (in bold)

comparing cynicism scores only. This indicates that cynicism is an underlying construct that is important in the relationship between grit and burnout.

Factors such as gender, religiosity, and social support have been shown to associated with burnout (or the lack thereof) [26-29]. Similar to the majority of studies dedicated to gender, the results of this study show that gender shares no relationship with burnout [20, 46, 68-70].

While TFA, social support and religiosity have shown to be protective against burnout in several studies [2629 ], our results indicate no correlation. This could be an artefact due to the small sample size of our study. There could exist other nuanced factors which might interact with these resources which have not been investigated.

Our study is aligned with other studies which suggest that grit is a protective factor against burnout. Previous studies have shown that gritty doctors in the UK display less burnout [24]. Surgical residents in the USA that have a below-median level of grit tend to report not being satisfied with their residency and also have a higher attrition rate [71]. A similar study in Australia proved that GP registrars with high levels of resilience are associated with less burnout, anxiety, and stress [72]. These studies were cross-sectional and did not consider the temporal effect of grit on burnout. This current study, shows that grit is able to predict the MBI-SS scores of medical students over an academic year, further fortifying the link between grit and burnout.

To the best of our knowledge, this study is the first to demonstrate a relationship between grit and burnout in a Singaporean medical school. Singapore is a highlystressed country [73-75], with a good percentage of healthcare workers admitting to being 'burnt-out' [7679]. The job demands in medical school and the healthcare sector have been proven to be overwhelming and result in burnout if not managed appropriately. Hence, identifying any protective factors against burnout in such a highly-strung society is key for the mental well-being of Singaporean healthcare workers. Training to improve one's grit might assist in ameliorating the immense job demands and hence preventing the onset of burnout.

Short term solutions to burnout, such as getting time off from work, may not necessarily solve the problem of burnout [80]. In a recent study, burnout rates did not differ when French urologists were given 'protected time' away from work [81]. This would indicate that burnout is not a result of overworking. Efforts to improve and develop grit might provide a better chance to protect against burnout than short-term, temporary solutions. More attention should be channeled to developing grit amongst medical students.

Individuals working towards a common goal, given ample opportunity for deliberate practice and reminders of their shared purpose have been suggested to develop grit as a group [82, 83]. The formation of a culture which promotes and breeds grit within an organization would be a stronger force to withstand burnout rather than just training individuals to be grittier. The setting up of a positive grit culture in medical school might reduce the problem of burnout. Grittier students fare better in exams, find a sense of purpose in their desired vocation, and are more optimistic than less grittier students [82, 84]. All of these characteristics are traits which one expects from a competent physician.

\section{Limitations affecting conclusions}

This longitudinal study has allowed us to reach 2 main conclusions; 1) grittier students have a lower chance of facing burnout, and 2) a medical student with a grit score of $\geq 44$ has a $92 \%$ chance of not developing burnout. However, these conclusions were made through the lens of a single class with a small sample size $(n=59)$ in a single institution. The small sample size was further exacerbated by the lack of $100 \%$ response rate, which is common shortfall in online data collections [85]. The missing $6.3 \%$ could have skewed the results differently. 


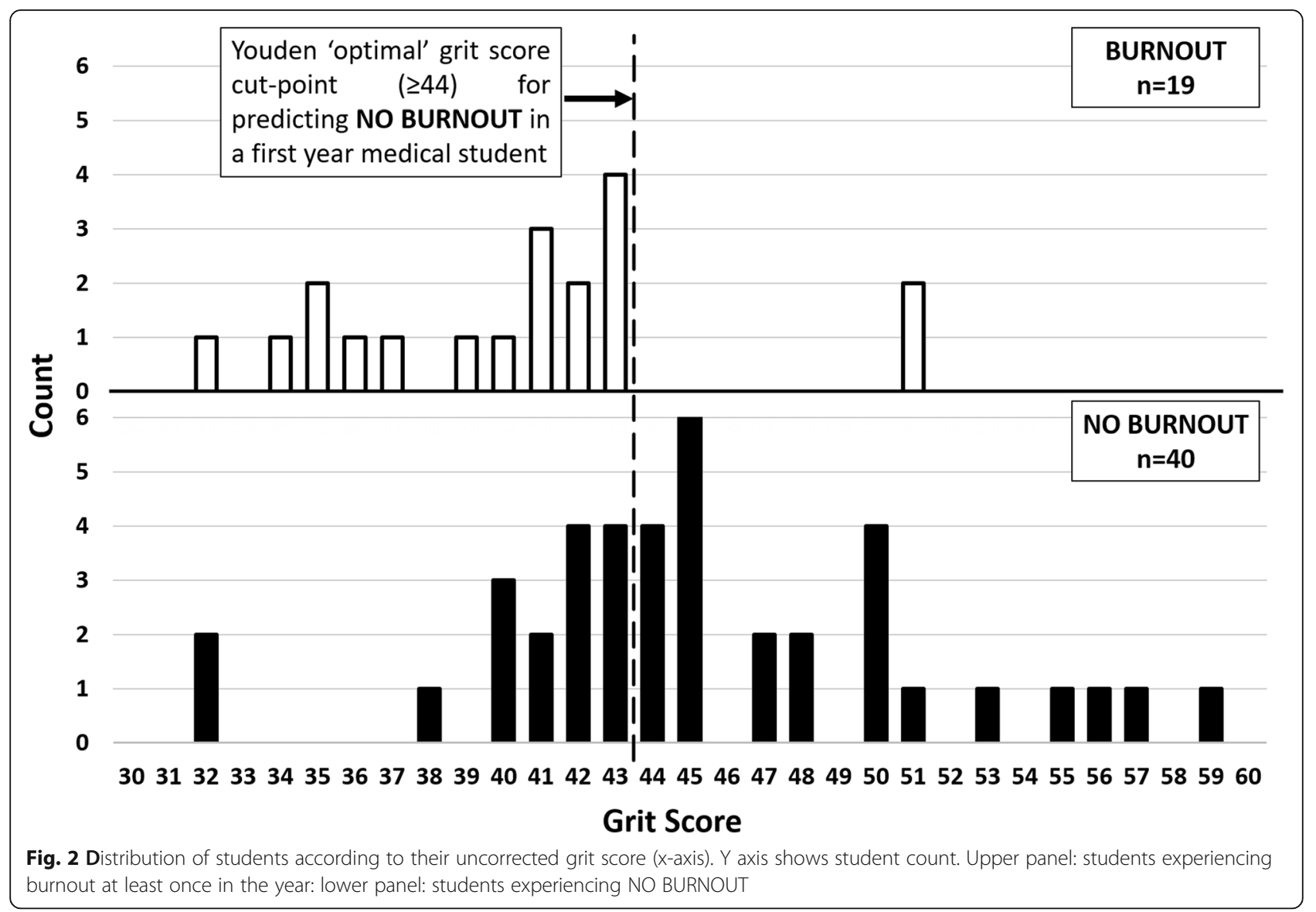

Other disadvantages of online collections include a short attention span and the inability to confirm the identiy of the survey taker. Burnout sampling points were also roughly aligned with the ends of courses. Burnout incidences might have differed if sampling points were changed. As a quantitative survey, we were limited in our ability to explore the rationales behind the student responses which could be more complex than the resources which were incorporated in the conceptual framework. A larger class size, and a study over multiple years, and replicating this study at multiple institutions would be required to validate the conclusions reached in this study as applicable to medical students in general.

\section{Abbreviations}

DUREL: Duke University Religion Index; MBI-SS: Maslach Burnout Inventory Student Survey; NPV: Negative Predictive Value; NUS: National University of Singapore; PPV: Positive Predictive Value; ROC: Receiving Operating Characteristic; TFA: Tolerance For Ambiguity; TBL: Team-Based-Learning; TAS: Tolerance for Ambiguity Scale

\section{Acknowledgements}

Not applicable.

\section{Authors' contributions}

PKHC, LSH, HWC, IJ, MUSM, AR, MV, DE, and SC, conceived and designed the study. MRJ and JA analysed the data and wrote the manuscript. All authors read and approved the final manuscript.

\section{Funding}

Not applicable.

\section{Availability of data and materials}

The datasets used and/or analysed during this study are available from the corresponding author upon reasonable request.

\section{Ethics approval and consent to participate}

This study was approved by the Institutional Review Board of the National University of Singapore (B-16-006). All subjects of the panel survey gave written consent for anonymised data to be used for publication purposes.

\section{Consent for publication}

Not applicable.

\section{Competing interests}

The authors declare that they have no competing interests.

\section{Author details}

'Office of Education, Duke-NUS Medical School, 8 College Rd., Level 3, Singapore 169857, Singapore. ${ }^{2}$ Singapore General Hospital, Singapore, Outram Road, Singapore 169608, Singapore. ${ }^{3}$ Department of Psychology and Neuroscience, Duke University School of Medicine, North Carolina 27708, Durham, USA.

Received: 3 May 2020 Accepted: 4 August 2020

Published online: 12 August 2020

\section{References}

1. WHO WHO. ICD-11 for mortality and morbidity statistics (Vervion 04/19). 2019

2. Maslach C, Jackson SE, Leiter MP. Maslach burnout inventory manual: consulting psychologists press Palo Alto, CA; 1996. 
3. Maslach C, Jackson SE, Leiter MP, Schaufeli WB, Schwab RL. Maslach burnout inventory: consulting psychologists press Palo Alto, CA; 1986.

4. Dyrbye LN, West CP, Satele D, Boone S, Tan L, Sloan J, et al. Burnout among U.S. medical students, residents, and early career physicians relative to the general U.S. population. Acad Med. 2014;89(3):443-51.

5. Alexandrova-Karamanova A, Todorova I, Montgomery A, Panagopoulou E, Costa P, Baban A, et al. Burnout and health behaviors in health professionals from seven European countries. Int Arch Occup Environ Health. 2016;89(7): 1059-75.

6. Shanafelt TD, Boone S, Tan L, Dyrbye LN, Sotile W, Satele D, et al. Burnout and satisfaction with work-life balance among US physicians relative to the general US PopulationBurnout and satisfaction with work-life balance. JAMA Intern Med. 2012;172(18):1377-85.

7. Kanai-Pak M, Aiken LH, Sloane DM, Poghosyan L. Poor work environments and nurse inexperience are associated with burnout, job dissatisfaction and quality deficits in Japanese hospitals. J Clin Nurs. 2008;17(24):3324-9.

8. Boudreau RA, Grieco RL, Cahoon SL, Robertson RC, Wedel RJ. The pandemic from within: two surveys of physician burnout in Canada. Can J Commun Mental Health. 2006;25(2):71-88.

9. Demir A, Ulusoy M, Ulusoy MF. Investigation of factors influencing burnout levels in the professional and private lives of nurses. Int J Nurs Stud. 2003; 40(8):807-27.

10. Popa F, Raed A, Purcarea VL, Lala A, Bobirnac G. Occupational burnout levels in emergency medicine--a nationwide study and analysis. J Med Life. 2010;3(3):207-15.

11. Tawfik DS, Profit J, Morgenthaler TI, Satele DV, Sinsky CA, Dyrbye LN, et al. Physician burnout, well-being, and work unit safety grades in relationship to reported medical errors. Mayo Clin Proc. 2018;93(11):1571-80.

12. lacovides A, Fountoulakis KN, Kaprinis S, Kaprinis G. The relationship between job stress, burnout and clinical depression. J Affect Disord. 2003; 75(3):209-21.

13. Panagioti M, Geraghty K, Johnson J, Zhou A, Panagopoulou E, ChewGraham C, et al. Association between physician burnout and patient safety, professionalism, and patient satisfaction: a systematic review and metaanalysis. JAMA Intern Med. 2018;178(10):1317-31.

14. Brazeau CMLR, Schroeder R, Rovi S, Boyd L. Relationships between medica student burnout, empathy, and professionalism climate. Acad Med. 2010; 85(10):S33-S6

15. Pagnin D, De Queiroz V, Oliveira Filho MAD, Gonzalez NVA, Salgado AET, Oliveira BCE, et al. Burnout and career choice motivation in medical students. Med Teach. 2013;35(5):388-94.

16. DeLuca A. Burnout, coping, and intention to leave college in undergraduate students: A cross-ethnic perspective: ProQuest Dissertations Publishing; 2004.

17. Dyrbye LN, Thomas MR, Massie FS, Power DV, Eacker A, Harper W, et al. Burnout and suicidal ideation among U.S. medical students. Ann Intern Med. 2008;149(5):334-41

18. Brazeau CM, Shanafelt T, Durning SJ, Massie FS, Eacker A, Moutier C, et al. Distress among matriculating medical students relative to the general population. Acad Med. 2014;89(11):1520-5.

19. Scholz M, Neumann C, Steinmann C, Hammer CM, Schroder A, Essel N, et al. Development and correlation of work-related behavior and experience patterns, burnout and quality of life in medical students from their freshmanship to the first state examination. Psychother Psychosom Med Psychol. 2015;65(3-4):93-8.

20. Cecil J, McHale C, Hart J, Laidlaw A. Behaviour and burnout in medical students. Med Educ Online. 2014:19:25209.

21. Santen SA, Holt DB, Kemp JD, Hemphill RR. Burnout in medical students: examining the prevalence and associated factors. South Med J. 2010;103(8): 758-63.

22. Dyrbye LN, Thomas MR, Harper W, Massie FS Jr, Power DV, Eacker A, et al. The learning environment and medical student burnout: a multicentre study. Med Educ. 2009;43(3):274-82

23. Duckworth AL, Peterson C, Matthews MD, Kelly DR. Grit: perseverance and passion for long-term goals. J Pers Soc Psychol. 2007;92(6):1087-101.

24. Halliday L, Walker A, Vig S, Hines J, JJPmj B. Grit and burnout in UK doctors: a cross-sectional study across specialties and stages of training. Postgrad Med J. 2017;93(1101):389-94.

25. Damgaard MT, Nielsen HS. Nudging in education. Econ Educ Rev. 2018;64: 313-42.
26. Hancock J, Mattick K. Tolerance of ambiguity and psychological well-being in medical training: a systematic review. Med Educ. 2020;54(2):125-37.

27. Fehring RJ, Cheever KH, German K, Philpot C. Religiosity and sexual activity among older adolescents. J Relig Health. 1998;37(3):229-47.

28. Ayele H, Mulligan T, Gheorghiu S, Reyes-Ortiz C. Religious activity improves life satisfaction for some physicians and older patients. J Am Geriatr Soc. 1999;47(4):453-5.

29. Kim B, Jee S, Lee J, An S, Lee SM. Relationships between social support and student burnout: a meta-analytic approach. Stress Health. 2018;34(1):127-34.

30. Bakker AB, Demerouti E. The job demands-resources model: state of the art. J Manag Psychol. 2007:22(3):309-28.

31. Huang J, Wang Y, You X. The job demands-resources model and job burnout: the mediating role of personal resources. Curr Psychol. 2016;35(4): 562-9.

32. Xanthopoulou D, Bakker AB, Demerouti E, Schaufeli WB. The role of personal resources in the job demands-resources model. Int J Stress Manag. 2007;14(2):121.

33. Xanthopoulou D, Bakker AB, Demerouti E, Schaufeli WB. Reciprocal relationships between job resources, personal resources, and work engagement. J Vocat Behav. 2009;74(3):235-44.

34. Bakker $A B$, Demerouti $E$, Verbeke W. Using the job demands-resources model to predict burnout and performance. Hum Resourc Manag. 2004; 43(1):83-104.

35. Duckworth AL, Quinn PD. Development and validation of the short grit scale (grit-s). J Pers Assess. 2009;91(2):166-74.

36. Hood RW, Hill PC, Spilka B. The psychology of religion: an empirical approach. 4th ed. New York: Guilford Press; 2009.

37. Salmoirago-Blotcher E, Fitchett G, Leung K, Volturo G, Boudreaux E, Crawford $\mathrm{S}$, et al. An exploration of the role of religion/spirituality in the promotion of physicians' wellbeing in emergency medicine. Prev Med Rep. 2016:3:189-95.

38. Wachholtz A, Rogoff $M$. The relationship between spirituality and burnout among medical students. J Contemp Med Educ. 2013;1(2):83-91.

39. Somech A, Miassy-Maljak N. The relationship between religiosity and burnout of principals: the meaning of educational work and role variables as mediators. Soc Psychol Educ. 2003;6(1):61-90.

40. Antonucci TC. Social support and social relationships. Handbook Aging Soc Sci. 1990:205-26.

41. Thompson G, McBride RB, Hosford CC, Halaas G. Resilience among medical students: the role of coping style and social support. Teach Learn Med. 2016;28(2):174-82

42. Caulfield M, Andolsek K, Grbic D, Roskovensky L. Ambiguity tolerance of students matriculating to U.S. medical schools. Acad Med. 2014;89(11):1526-32.

43. Kuhn G, Goldberg R, Compton S. Tolerance for uncertainty, burnout, and satisfaction with the career of emergency medicine. Ann Emerg Med. 2009; 54(1):106-13 e6

44. Backović DV, Zivojinović Jl, Maksimović J, Maksimović M. Gender differences in academic stress and burnout among medical students in final years of education. Psychiatr Danub. 2012;24(2):175-81.

45. Worly B, Verbeck N, Walker C, Clinchot D, Keder L, Steinauer J. Gender differences in medical Students' experience of burnout, perceived stress, and empathic concern. Obstet Gynecol. 2017;130:61S.

46. Purvanova RK, Muros JP. Gender differences in burnout: a meta-analysis. J Vocat Behav. 2010;77(2):168-85.

47. Altannir Y, Alnajiar W, Ahmad SO, Altannir M, Yousuf F, Obeidat A, et al. Assessment of burnout in medical undergraduate students in Riyadh, Saudi Arabia. BMC Med Educ. 2019;19(1):34.

48. Dahlin M, Joneborg N, Runeson B. Performance-based self-esteem and burnout in a cross-sectional study of medical students. Med Teach. 2007; 29(1):43-8.

49. Schaufeli WB, Martinez IM, Pinto AM, Salanova M, Bakker AB. Burnout and engagement in university students: a cross-national study. J Cross-Cult Psychol. 2002;33(5):464-81.

50. Cordes CL, Dougherty TW. A review and an integration of research on job burnout. Acad Manag Rev. 1993;18(4):621-56.

51. Rafferty JP, Lemkau JP, Purdy RR, Rudisill JR. Validity of the Maslach burnout inventory for family practice physicians. J Clin Psychol. 1986; 42(3):488-92.

52. Cortez AR, Winer LK, Kassam A-F, Kuethe JW, Athota KP, Quillin RC. The Impact of Medical Student Burnout on Surgery Clerkship Performance. J Surg Educ. 2019 
53. Tedesqui RAB, Young BW. Investigating grit variables and their relations with practice and skill groups in developing sport experts. High Ability Stud. 2017;28(2):167-80

54. Koenig H, Parkerson GR Jr, Meador KG. Religion index for psychiatric research. Am J Psychiatry. 1997;154(6):885-6.

55. Zimet GD, Dahlem NW, Zimet SG, Farley GK. The multidimensional scale of perceived social support. J Pers Assess. 1988;52(1):30-41.

56. Geller G, Tambor ES, Chase GA, Holtzman NA. Measuring physicians' tolerance for ambiguity and its relationship to their reported practices regarding genetic testing. Med Care. 1993;31(11):989-1001.

57. Bolat MS, Yuruk E, Cinar O, Akdeniz E, Altunrende F, Ozkuvanci U, et al. The prevalence of burnout syndrome among Turkish urologists: results of a Nationwide survey. Turkish J Urol. 2018:1-8.

58. Castanheira F, Chambel MJ. Reducing burnout in call centers through HR practices. Hum Resour Manag. 2010:49(6):1047-65.

59. Association AP. Diagnostic and statistical manual of mental disorders (DSM$\left.5^{\oplus}\right)$ : American psychiatric pub; 2013

60. Iwanicki EF, Schwab RL. A cross validation study of the Maslach burnout inventory. Educ Psychol Meas. 1981:41(4):1167-74.

61. Koenig HG, Büssing $A$. The Duke University religion index (DUREL): a fiveitem measure for use in Epidemological studies. Religions. 2010;1(1):78-85.

62. Zimet GD, Powell SS, Farley GK, Werkman S, Berkoff KA. Psychometric characteristics of the multidimensional scale of perceived social support. J Pers Assess. 1990;55(3-4):610-7.

63. Lee RT, Ashforth BE. A meta-analytic examination of the correlates of the three dimensions of job burnout. J Appl Psychol. 1996;81(2):123-33.

64. Green DE, Walkey FH, Taylor AJ. The three-factor structure of the Maslach burnout inventory: a multicultural, multinational confirmatory study. J Soc Behav Pers. 1991;6(3):453.

65. Schaufeli WB, Bakker AB, Hoogduin K, Schaap C, Kladler A. On the clinical validity of the Maslach burnout inventory and the burnout measure. Psychol Health. 2001;16(5):565-82.

66. Roelofs J, Verbraak M, Keijsers GP, De Bruin MB, Schmidt AJ. Psychometric properties of a Dutch version of the Maslach burnout inventory general survey (MBI-DV) in individuals with and without clinical burnout. Stress Health. 2005:21(1):17-25.

67. Maslach C, Leiter MP, Schaufeli W. Measuring burnout. The Oxford handbook of organizational well being. 2008.

68. Shadid A, Shadid AM, Shadid A, Almutairi FE, Almotairi KE, Aldarwish T, et al Stress, burnout, and associated risk factors in medical students. Cureus. 2020;12(1).

69. Amir E, Kumari S, Olivetta U, Mansoor M. Burnout and depression among medical students at historically black colleges and universities (HBCU) hospital system. Int J Psychol Behav Anal 2018;2018.

70. Galán F, Sanmartín A, Polo J, Giner L. Burnout risk in medical students in Spain using the Maslach burnout inventory-student survey. Int Arch Occup Environ Health. 2011:84(4):453-9.

71. Burkhart RA, Tholey RM, Guinto D, Yeo CJ, Chojnacki KA. Grit: a marker of residents at risk for attrition? Surgery. 2014;155(6):1014-22.

72. Cooke GPE, Doust JA, Steele MC. A survey of resilience, burnout, and tolerance of uncertainty in Australian general practice registrars. BMC Med Educ. 2013;13(1):2.

73. Teo J. Burnout likely a common problem here, Singaporeans among most stressed at work globally. Straits Times. 20192 June 2019.

74. Neo RW. Sleep-deprived Singaporean workers among most stressed globally: Survey. TODAY. 201926 MARCH, 2019.

75. Lim S. A whopping 92\% of working Singaporeans are stressed - and women are prioritising families over themselves, study finds. Bus Insider Singapore 2019 26, 2019.

76. Ang SY, Dhaliwal SS, Ayre TC, Uthaman T, Fong KY, Tien CE, et al. Demographics and Personality Factors Associated with Burnout among Nurses in a Singapore Tertiary Hospital. Biomed Res Int. 2016;2016:6960184-.

77. Yang S, Meredith P, Khan A. Stress and burnout among healthcare professionals working in a mental health setting in Singapore. Asian J Psychiatr. 2015;15:15-20.

78. Lee PT, Loh J, Sng G, Tung J, Yeo KK. Empathy and burnout: a study on residents from a Singapore institution. Singap Med J. 2017;59(1):50-4.

79. Koh M. Burnout in palliative care: a National Study of palliative care practitioners in Singapore (S753). J Pain Symptom Manag. 2015:49(2):435.

80. Abu Baker J. Coping one day and crying the next: Work-related burnout is real. CNA. 201905 June 2019
81. Gas J, Bart S, Michel P, Peyronnet B, Bergerat S, Olivier J, et al. Prevalence of and predictive factors for burnout among French urologists in training. Eur Urol. 2019;75(4):702-3.

82. Duckworth A. Grit: the power of passion and perseverance. First Scribner hardcover ed. New York: Scribner; 2016

83. Lee TH, Duckworth AL. Organizational grit: turning passion and perseverance into performance: the view from the health care industry. 2018;96(5):98

84. Strayhorn TL. What role does grit play in the academic success of black male collegians at predominantly white institutions? J Afr Am Stud. 2014; 18(1):1-10.

85. Cantrell MA, Lupinacci P. Methodological issues in online data collection. J Adv Nurs. 2007:60(5):544-9.

\section{Publisher's Note}

Springer Nature remains neutral with regard to jurisdictional claims in published maps and institutional affiliations.
Ready to submit your research? Choose BMC and benefit from:

- fast, convenient online submission

- thorough peer review by experienced researchers in your field

- rapid publication on acceptance

- support for research data, including large and complex data types

- gold Open Access which fosters wider collaboration and increased citations

- maximum visibility for your research: over $100 \mathrm{M}$ website views per year

At BMC, research is always in progress.

Learn more biomedcentral.com/submissions 